\title{
Peripartum cardiomyopathy: what is the role of the magnetic resonance imaging?
}

\section{Miocardiopatía periparto: ¿cuál es el papel de la resonancia magnética nuclear?}

\author{
Grecia I. Raymundo-Martínez ${ }^{1}$, Rodrigo Gopar-Nieto ${ }^{1}$, Sergio Raul Scuri², \\ Laura L. Rodríguez-Chavez ${ }^{3}$ and Nilda Espinola-Zavaleta ${ }^{4,5 *}$ \\ ${ }^{1}$ Department of Medical Education, Instituto Nacional de Cardiología Ignacio Chávez, Mexico City, Mexico; ${ }^{2}$ Department of Medical Education, \\ Hospital Italiano de La Plata, Buenos Aires, Argentina; ${ }^{3}$ Out-Patient Clinic; ${ }^{4}$ Department of Nuclear Cardiology. Instituto Nacional de Cardiología \\ Ignacio Chávez, Mexico City, Mexico; ${ }^{5}$ Department of Echocardiography, ABC Medical Center I.A.P, Mexico City, Mexico
}

A twenty-seven year-old pregnant female with history of smoking for the last 5 years. In the seventh month of pregnancy began with progressive dyspnea and ankle edema. At her initial evaluation, she had acute heart failure, with bilateral pleural effusion and apex displaced to the $6^{\text {th }}$ intercostal space. On auscultation, systolic murmur was heard in tricuspid and mitral focus grade II/ IV radiated to axilla. $\mathrm{N}$-terminal pro-B-type natriuretic peptide was of $14,530 \mathrm{pc} / \mathrm{dl}$. Electrocardiogram revealed sinus tachycardia with heart rate of $110 \mathrm{bpm}$. The chest $\mathrm{X}$-ray showed cardiomegaly with cardiothoracic index of 0.57 , pulmonary venocapillary hypertension, and right pleural effusion. Transthoracic echocardiogram showed dilation of four cavities, global hypokinesia, left ventricular systolic dysfunction with ejection fraction of $31 \%$, and mild mitral and tricuspid regurgitation. A cardiac magnetic resonance imaging (CMRI) corroborated the dilation of the four cavities and also revealed anteroseptal and inferoseptal intramyocardial late gadolinium enhancement (LGE), with the left ventricular ejection fraction of $19 \%$ and the right ventricular ejection fraction of $13 \%$, bilateral pleural effusion, and pericardial effusion (Fig. 1), compatible with peripartum cardiomyopathy (PPCP).
After 1 year of delivery, she is in NYHA functional Class III, despite complete medical treatment for heart failure.

PPCP has an incidence of 1:100-1:1500. Even though it is more common in women older than 30 years, it has been reported across a wide range of age groups. Most symptoms occur in the context of a normal pregnancy. About $19 \%$ of patients may present with symptoms before the past gestational months. It develops during the past 3 months until 6 months after delivery. It must be suspected in a younger age. Among the physiopathological explanations are nutritional deficiency, abnormalities in small coronary arteries, hormonal effects, toxemia, and maternal response to fetal antigen. Clinical follow-up is very variable ${ }^{1-3}$. LGE seems to be associated with a poor prognosis in the setting of PPCM. CMRI seems to have promising practical implications in the diagnosis and prognosis of PPCM patients. Up to $50 \%$ of cases show complete recovery of the left ventricular systolic function after 6 months of delivery, but the other $50 \%$ develop progressive dilation and ventricular dysfunction that leads to premature death due to heart failure ${ }^{4,5}$. In

\section{Correspondence:}

*Nilda Espinola-Zavaleta

E-mail: niesza2001 @ hotmail.com
Available online: 19-03-2019 Arch Cardiol Mex. 2019;89(1):74-75 www.archivoscardiologia.com
s un artículo Open Access bajo la licencia CC BY-NC-ND (http://creativecommons.org/licenses/by-nc-nd/4.0/) 


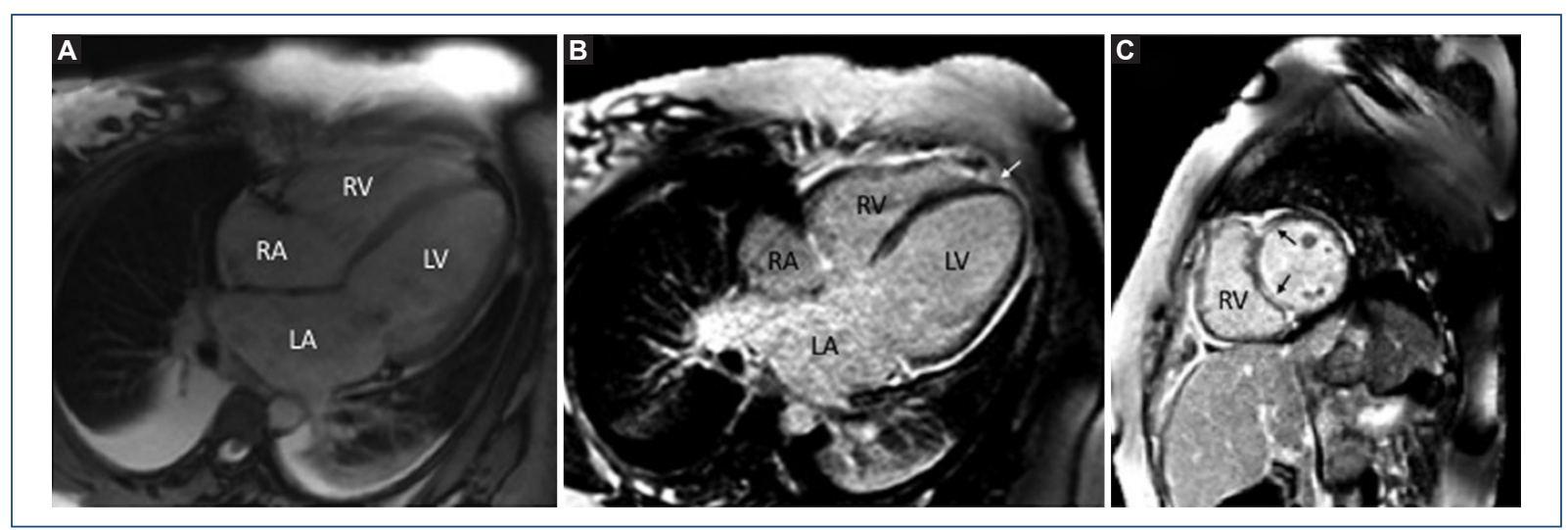

Figure 1. A: Dilation of cardiac cavities, pericardial effusion, and bilateral pleural effusion was observed. B: Four chambers, C: Short axis at the level of both ventricles, showing intramyocardial anteroseptal and inferoseptal (black arrows) late gadolinium enhancement, also in the site of the left ventricular junction with the right ventricle (white arrow).

our patient, CMRI demonstrated LGE, a parameter of poor prognosis and she is in chronic heart failure.

\section{Funding}

No funding.

\section{Conflicts of interest}

None declared.

\section{Ethical disclosures}

Protection of human and animal subjects. The authors declare that no experiments were performed on humans or animals for this study.
Confidentiality of data. The authors declare that they have followed the protocols of their work center on the publication of patient data.

Right to privacy and informed consent. The authors declare that no patient data appear in this article.

\section{References}

1. Koenig T, Hilfiker-Kleiner D, Bauersachs J. Peripartum cardiomyopathy. Herz. 2018;43:431-7.

2. Asad ZU, Maiwand M, Farah F, Dasari TW. Peripartum cardiomyopathy: a systematic review of the literature. Clin Cardiol. 2018;41:693-7.

3. Shah M, Ram P, Lo KB, et al. Etiologies, predictors, and economic impact of 30-day readmissions among patients with peripartum cardiomyopathy. Am J Cardiol. 2018;122:156-65.

4. Cruz MO, Briller J, Hibbard JU. New insights in peripartum cardiomyopathy. Obstet Gynecol Clin N Am. 2018;45:281-98.

5. Goland S, Elkayam U. Peripartum cardiomyopathy: approach to management. Curr Opin Cardiol. 2018;33:347-53. 